\section{Nitrogen enrichment during exhumation: new insights from multiphase inclusions in subducted rocks (Cabo Ortegal Complex, NW- Spain)}

TAMÁS SPRÁNITZ ${ }^{1}$, JOSÉ ALBERTO PADRÓNNAVARTA $^{2,3}$, CSABA SZABÓ $^{4}$ AND MARTA BERKESI ${ }^{1}$

${ }^{1}$ Lithosphere Fluid Research Lab, Eötvös University

${ }^{2}$ CSIC-Universidad de Granada

${ }^{3}$ Université de Montpellier \& CNRS

${ }^{4}$ Eötvös University

Presenting Author: spratom.elte@gmail.com

Exhumed rocks that experienced high pressure metamorphism during subduction processes, such as those outcropping in Cabo Ortegal Complex (COC), provide direct information on signatures of volatiles at subduction conditions. Primary fluid inclusions of such metamorphic rocks yield evidence on the composition of former subduction fluids, an essential observation to constrain the volatile cycling.

We have carried out a detailed study on primary multiphase inclusions (MPI) in garnet from eclogites and granulites of the COC to characterize such fluids. MPI are hosted by garnet porphyroblasts along a growth zone or in $3 \mathrm{D}$ clusters indicating their primary origin of HP metamorphic conditions. These inclusions are characterized by irregular to negative crystal shape with 1-40 $\mu \mathrm{m}$ size. Detailed Raman spectroscopic imaging, SEM-EDS and FIB-SEM confirmed that MPI have a uniform phase assemblage and nearly constant volume proportions dominated by the intergrowth of $\mathrm{Fe}-\mathrm{Mg}-\mathrm{Ca}$-carbonates and phyllosilicates (pyrophyllite, chlorite and margarite) together with $\mathrm{N}_{2}-\mathrm{CH}_{4}-\mathrm{CO}_{2}$ fluid among the solid phases (Fig. 1.). Our results indicate that these solid phases are the result of postentrapment reactions of a volatile-rich fluid and the host garnet and thus can be referred to as step-daughter minerals. Mass balance calculations showed that the originally trapped fluid was composed of $\mathrm{H}_{2} \mathrm{O}$ and $\mathrm{CO}_{2}$ as carbonates and hydrous silicates have been produced by carbonation and hydration reactions. The lack of detectable $\mathrm{H}_{2} \mathrm{O}$ in the MPI suggests that fluid-garnet interaction ceases when all $\mathrm{H}_{2} \mathrm{O}$ is consumed in the reaction. At that point the composition of the residual fluid will be highly enriched in $\mathrm{N}_{2}$, as evidenced in the fluid phase of all MPI analyzed. Similar consumption of $\mathrm{H}_{2} \mathrm{O}$ and partly $\mathrm{CO}_{2}$ during retrograde evolution would designate a horizon of a fluid regime dominated or at least elevated by nitrogen.

Our findings indicate that such mechanism may play an important role in global nitrogen cycling and provide significant contribution to nitrogen supply to overlying subsurface/surface environments during devolatilization in forearc regions (springs and outflow of mud volcanoes) of convergent margins.

This research was supported by the NRDIO_FK research fund nr. 132418.

Fig. 1. Photomicrograph and 3D reconstruction of an MPI in eclogite, exposed with FIB-SEM.

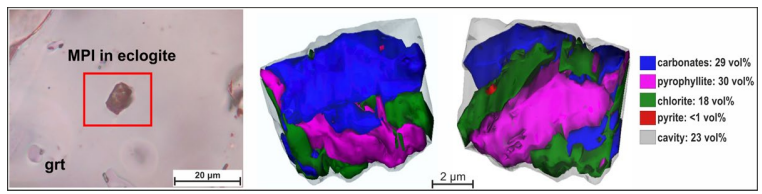

